\title{
Integrating control generated by positive and negative reinforcement on an operant baseline: Appetitive-aversive interactions
}

\author{
STANLEY J. WEISS \\ The American University, Washington, D.C. \\ and \\ CHARLES W. SCHINDLER \\ NIDA Addiction Research Center, Baltimore, Maryland
}

\begin{abstract}
The interaction of opposing motivational states was measured within a design in which rats barpressed for food in one stimulus and to avoid shock in another. Tone and light discriminative stimuli (Sds) were counterbalanced over incentive conditions. Extinction eliminated responding when neither Sd was present. To minimize the influence of competing peripheral operants or reinforcer-elicited behaviors during appetitive-aversive interactions, contingency parameters were manipulated to generate similar rates and patterns of barpressing in both Sds and stimuluscompounding tests were administered in extinction. On these tests, rates in tone, light, and tone plus light $(\mathrm{T}+\mathrm{L})$ were equivalent. In contrast, when the same reinforcer (i.e., food or shock avoidance) maintained comparable training rates in tone and in light, in testing, $T+L$ controlled double the rates of the single stimuli-strong additive summation. These results were strikingly similar to those of single-incentive experiments concerned with the contribution of excitatory and inhibitory incentive states to the results of stimulus compounding. Simultaneously presenting two Sds whose implicit stimulus-reinforcer (S-Sr) contingencies were arranged to make them, respectively, conditioned appetitive and aversive excitors (present experiment) produced test results comparable to those of two Sds whose implicit S-S ${ }^{r}$ contingencies were arranged to make them both conditioned inhibitors. Reciprocal antagonism between these two motive states more than neutralizes them. It appears to produce a negative (i.e., an inhibitory) motive state.
\end{abstract}

One of the important objectives of psychology is to understand, that is, to be able to predict and control, behavior. Unfortunately, the ability to predict when a particular operant will be emitted, and when it will not, does not necessarily reflect an appreciation of the multiple factors that could be contributing to the stimulus control generated in any particular situation. This was clearly revealed in a series of experiments in which a comparison of baseline rates to each of two discriminative stimuli (Sds) as a measure of stimulus control was supplemented by stimulus-compounding assays in which the single Sds were presented simultaneously for the first time (Weiss, 1969, 1971, Experiment 2; Weiss \& Van Ost, 1974).

In those experiments, the baseline rates of three groups of rats were indistinguishable from each other in spite of the fact that each group was trained on a different threecomponent schedule. In all three groups, rats barpressed

This research was supported in part by an American University Faculty Research Grant and in part by NIMH Grant MH-16853, both awarded to the senior author. It was presented at the $\mathbf{1 9 8 5}$ convention of the Psychonomic Society in New Orleans. The authors appreciate the helpful comments of David A. Thomas, Richard Warren, and Leigh Panlilio, on many aspects of this manuscript. Reprints may be obtained from Stanley J. Weiss, Department of Psychology, The American University, Washington, DC 20016. at moderate stable rates in tone and in light, whereas they ceased pressing in the simultaneous absence of these stimuli $(\overline{\mathrm{T}}+\overline{\mathrm{L}})$. The independent variable in those studies was the proportion of total session food reinforcements received in tone and light components relative to $\overline{\mathrm{T}}+\overline{\mathrm{L}}$ : $100 \%, 50 \%$, or $0 \%$. The dependent variable was the distribution of responses among tone, light, and tone plus light $(\mathrm{T}+\mathrm{L})$ on a stimulus-compounding test.

When the rats received $100 \%$ of their reinforcers in tone and in light, a variable-interval (VI) schedule was programmed during these stimuli while $\overline{\mathrm{T}}+\overline{\mathrm{L}}$ was associated with extinction (EXT). This was a multiple VI VI EXT schedule (Weiss, 1969, 1971). When the rats received approximately $50 \%$ of their reinforcers in tone and in light, they were reinforced as frequently in these components for responding on a VI schedule as they were for not barpressing on a differential reinforcement of other behavior (DRO) schedule in $\overline{\mathrm{T}}+\overline{\mathrm{L}}$. This was a multiple VI VI DRO schedule (Weiss, 1971; Weiss \& Van Ost, 1974). Finally, when the rats received $0 \%$ of their reinforcers in tone and in light, they were on a schedule in which they had to barpress during these stimuli to produce, on a VI schedule, $\overline{\mathrm{T}}+\overline{\mathrm{L}}$. In $\overline{\mathrm{T}}+\overline{\mathrm{L}}$ they were reinforced with food on a DRO contingency. This was a chain VI DRO schedule (Weiss \& Van Ost, 1974) in which all reinforcers were 
received in $\bar{T}+\overline{\mathrm{L}}$. The strategy of comparing stimuluscompounding assays from these different baselines across experiments is justified by the reliable reproduction of previously demonstrated effects of compounding in each experiment that tested a new baseline and the nonoverlapping stimulus-compounding test results over baselines.

On all three baselines described above, the tone and the light were comparable as Sds; each controlled an increase in barpressing, whereas responding essentially ceased in $\overline{\mathbf{T}}+\overline{\mathrm{L}}$. However, according to a stimulus-reinforcer $\left(\mathbf{S}-\mathrm{S}^{\mathbf{r}}\right)$ contingency analysis of these baselines, the changes in probability of reinforcement implicit in the tone and light would establish conditioned incentive properties to the Sds through a classical conditioning mechanism (Bindra, 1972; Rescorla \& Solomon, 1967; Weiss, 1978). When the probability of reinforcement in tone or light $\left[P\left(S^{T} \mid T / L\right)\right]$ was greater than the probability of reinforcement in $\bar{T}+\overline{\mathrm{L}}$ $\left.\left[P\left(S^{r}\right) \mid \bar{T}+\bar{L}\right)\right]$, as in the $100 \%$ group, conditions were appropriate for generating excitatory appetitive-incentive properties to tone and light. However, in the $50 \%$ group, since reinforcement probability did not change in tone and light $\left[P\left(S^{r} \mid T / L\right)=P\left(S^{r} \mid T+\bar{L}\right)\right]$, no differential incentive properties should have been conditioned to these stimuli. Finally, in the $0 \%$ group, inhibitory incentive properties would have been generated to tone and light because $\mathbf{P}\left(\mathbf{S}^{\mathrm{I}} \mid \mathrm{T} / \mathrm{L}\right)$ was less than $\mathbf{P}\left(\mathbf{S}^{\mathrm{T}} \mid \overline{\mathbf{T}}+\overline{\mathrm{L}}\right)$.

Figure 1 (adapted from Weiss \& Van Ost, 1974) presents the nonoverlapping (see range bars) stimuluscompounding test results from these groups in terms of the percentage of total test responses emitted to the $T+L$ compound. The influence of the incentive factor on behavior is evident since the discriminative function of the tone and the light-barpress increase-was comparable over groups. With both response and reinforcement increasing in tone and light, relative to $\bar{T}+\bar{L}, T+L$ produced three times the rate of the single stimuli (Point A,B). When tone and light each controlled an increase in barpressing but signaled no change in reinforcement, $T+L$ produced only twice the rate of the single stimuli (Point B,C). (This additivity might be considered a "pure" product of only the discriminative control of operant rate increase by the stimuli compounded. Therefore, any lesser additivity to $T+L$ when the single stimuli are discriminative for comparable response increases, relative to the $\overline{\mathrm{T}}+\overline{\mathrm{L}}$ rate, might be considered a measure of a response-inhibiting process.)

In the final incentive condition, in which the tone and light each controlled an increase in response rate but signaled a decrease in reinforcement, these stimuli could be considered conditioned appetitive inhibitors since $\mathrm{P}\left(\mathrm{S}^{\mathrm{I}} \mid \mathrm{T} / \mathrm{L}\right)<\mathrm{P}\left(\mathrm{S}^{\mathrm{s}} \mid \overline{\mathrm{T}}+\overline{\mathrm{L}}\right)$. In testing, $\mathrm{T}+\mathrm{L}$ controlled no summation after this training. Rates to $T+L$, tone, and light were equivalent for these subjects (Point $D$ of Figure 1 ). In comparison to the $100 \%$ summation produced by $T+L$ when the single stimuli signaled no change in reinforcement, when these stimuli signaled a reduction to zero in reinforcement, summation was eliminated. This total elimination of summation could be interpreted as re-

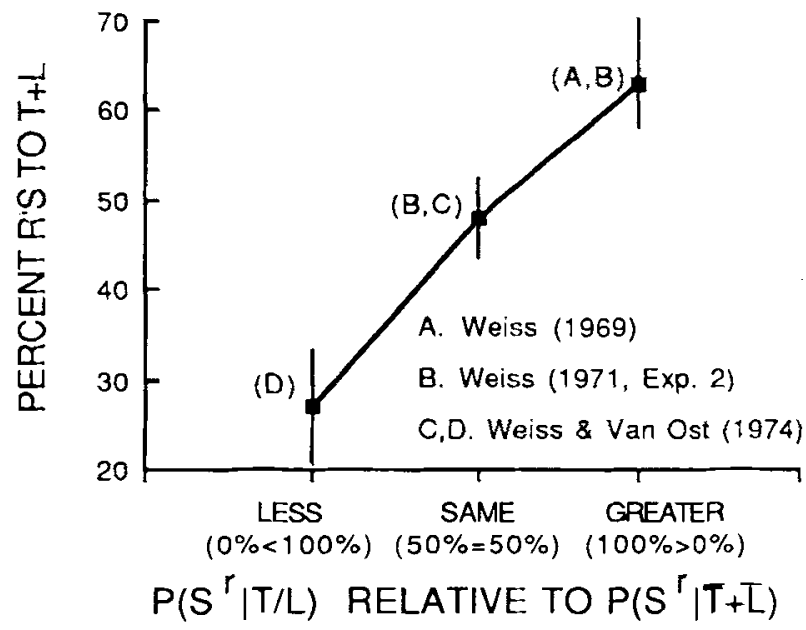

Figure 1. Percentage of responses emitted to tone plus light $(T+L)$ on a stimulus-compounding test as a percentage of the total responses to tone, light, and $T+L$. The $T+L$ percentage is presented as a function of the probability of receiving reinforcement in tone and in light $\left(P: S^{r} \mid T / L\right)$ relative to that of reinforcement in the absence of tone and light $\left(\mathbf{P}: S^{r} \mid \bar{T}+\bar{L}\right)$. The numbers in parentheses represent the percentage of total session reinforcers received in $T / L$ and $\bar{T}+\bar{L}$, respectively, corrected for time in components. On all baselines, responses were emitted in tone and in light, whereas responding ceased in their simultaneous absence. The vertical lines through each point indicate the range of subject scores represented. (From "Response discriminative and reinforcement factors in stimulus control of performance on multiple and chained schedules of reinforcement," by S. J. Weiss and S. L. Van Ost, 1974, Learning \& Motivation, 5, 459-472. Copyright 1974 Academic Press. Adapted by permission.)

vealing the effects of two strong appetitive-conditioned inhibitors on a compounding test in which tone and light were discriminative for a rate increase. If these single stimuli did not control a rate increase, more traditional subtractive effects would be anticipated with these conditioned inhibitors (see Weiss, 1977, for an additive analogue of this effect). This total elimination of additive effects is not presented as the only test outcome when two conditioned inhibitors are compounded and the Sds control a rate increase on the training baseline. These summative effects are probably on a continuum such that, other variables being comparable, if $25 \%$ of the total session reinforcers were earned in tone and in light, relative to $\overline{\mathrm{T}}+\overline{\mathrm{L}}, \mathrm{T}+\mathrm{L}$ would be expected to control a summative effect somewhere intermediate to those of the $0 \%$ and $50 \%$ groups in Figure 1.

Only single-incentive, appetitive baselines have thus far been described, with tone and light each discriminative for comparable increases in barpressing on all three baselines. This type of baseline behavior can also be produced in a situation in which different classes of incentive maintain responding in each component. For example, barpressing could be maintained in tone by $\mathrm{VI}$ food reinforcement and in light by free-operant shock avoidance (FOA), whereas extinction eliminates barpressing in $\overline{\mathrm{T}}+\overline{\mathrm{L}}$. On this multiple VI FOA EXT schedule, contingency param- 
eters would be chosen that produce comparable response rates and patterning in tone and light Sds, as occurs when the same contingency is programmed in both Sds. However, in contrast to the baselines represented in Figure 1, on the proposed appetitive-aversive baseline, one stimulus would be considered a conditioned appetitive excitor and the other a conditioned aversive excitor.

Our understanding of the motivational state generated by this excitatory appetitive-aversive interaction might be enhanced by comparing the outcome of stimulus compounding in the proposed experiment with the variety of outcomes presented in Figure 1, in which appetitive incentives were systematically varied. The current experiment should reveal where, on the continuum of stimuluscompounding outcomes, the results of this appetitiveaversive interaction fall. This comparison of outcomes might permit us to relate the resulting appetitive-aversive interaction to a motivational state produced on a singleincentive baseline. This strategy is an attempt at scientific integration through the method of "functional contiguity" (Sidman, 1960). This is made possible by the body of related programmatic investigations concerned with excitatory and inhibitory incentive motivation in which stimulus compounding was the behavioral assay. The functional contiguity would be based on comparable stimulus-compounding test outcomes when the incentives maintaining responding in each component are qualitatively different, as in the proposed experiment, and when they are qualitatively the same, as in the studies of Figure 1. What would previous research with appetitiveaversive interactions lead us to anticipate on the stimuluscompounding test of the proposed experiment?

There are stimuli that attract the organism and others that repel it. Performances that produce the former stimuli are positively reinforced, whereas performances that terminate the latter are negatively reinforced. According to Konorski (1967), there are two interacting, reciprocally inhibitory motivational systems related to these different classes of reinforcement: appetitive and aversive, respectively. These systems can be activated by stimuli that signal these attractive and repelling events through classical conditioning as well as by the events themselves, or deprivation states. According to this formulation, when a behavior is maintained by one class of reinforcement, activating the other motivational system will inhibit that behavior. This has been demonstrated when behavior was maintained by positive or negative reinforcement.

In experiments reporting conditioned suppression, operant behavior is maintained by appetitive reinforcement and signaled shock is occasionally presented. After several signal-shock pairings, operant performance decreases during the signal (Davis, 1968; Estes \& Skinner, 1941), with the decrease accentuated when two independently conditioned shock-signaling stimuli are presented simultaneously (Miller, 1969; Van Houten, O'Leary, \& Weiss, 1970; Weiss \& Emurian, 1970). In a similar manner, when an operant performance is maintained by shock avoidance, the rate of that performance decreases in the presence of a stimulus that signals food (Bull, 1970; Grossen, Kostansek, \& Bolles, 1969; Overmier, Bull, \& Pack, 1971).

This reduction in the operant performance maintained by one class of reinforcer by a stimulus that activates the other motivational system has been widely interpreted in terms of reciprocally inhibiting motivational states (Dickinson \& Dearing, 1979; Dickinson \& Pearce, 1977; Konorski, 1967; Millenson \& de Villiers, 1972; Rescorla \& Solomon, 1967). However, whenever there is a reduction in operant performance in such situations, the possibility always exists that incompatible peripheral operants, rather than competing central motivational states, are responsible. For example, during a conditioned stimulus (CS) that predicts shock, the animal might be posturing itself to reduce the shock's aversiveness, and these postures could interfere with emission of the foodmaintained operant. Similarly, during a CS that predicts food, the animal might be emitting some preparatory foodacquisition behaviors, and these could interfere with avoidance. There are, however, experiments designed to confront this source of confounding.

Herrnstein and Sidman (1958) demonstrated a differential incentive effect when a CS for shock increased the operant rate of their monkeys' leverpressing to avoid shock but decreased the operant rates of those monkeys working for orange juice. Overmier et al., (1971) reported similar results in an experiment in which two groups of dogs were taught to panelpress when a tone was presented. One group pressed for food and the other pressed to avoid shock. In a subsequent phase of the study, hurdle jumping, maintained by shock avoidance, was enhanced during tone presentations in the group for which tone was shock-schedule associated but was reduced in the group for which tone was food-schedule associated. Because the tone was a discriminative stimulus for panelpressing for both groups, its differential effects on avoidance can be safely attributed to the motivational properties established to it by the qualitatively opposite reinforcers.

If the effects of an aversive CS [superimposed on an instrumental baseline] depend on the nature of the motivation for instrumental responding, ... [then different effects] can hardly be mediated solely by the pattern of peripheral responses conditioned to that CS. (Mackintosh, 1974, p. 83)

From this sketch of the appetitive-aversive interaction literature, we would expect that activating the appetitive and aversive motivational systems during $T+L$ on a stimulus-compounding test should produce reciprocal inhibition. If rates to tone, light, and $T+L$ are comparable on this test, we might relate reciprocal inhibition to the state generated by two conditioned inhibitors of the same incentive class, as reflected by Point D in Figure 1. On the other hand, if $T+L$ controls moderate additive summation, like that reflected by Point B,C of Figure 1, reciprocal inhibition might represent a "neutralized" state similar to that generated when no differential incentive properties are conditioned to the single stimuli. 
Table 1

Design of Experiment

\begin{tabular}{cccccc}
\hline \multirow{2}{*}{$\begin{array}{c}\text { Unchanged } \\
\text { Contingency }\end{array}$} & Stimulus & & \multicolumn{4}{c}{ Phase* $^{*}$} & 2 & 3 & 4 \\
\hline \cline { 3 - 6 } VI & Tone & VI & VI & VI & VI \\
& Light & FOA & VI & FOA & VI \\
& $\bar{T}+\overline{\mathrm{L}}$ & & Extinction in all phases \\
\multirow{3}{*}{ FOA } & Tone & FOA & FOA & FOA & FOA \\
& Light & VI & FOA VI & FOA \\
& $\bar{T}+\overline{\mathrm{L}}$ & & Extinction in all phases \\
\hline
\end{tabular}

Note-VI = variable-interval schedule; FOA $=$ free-operant avoidance schedule; $\overline{\mathrm{T}}+\overline{\mathrm{L}}=$ absence of tone and light. Schedule parameters are described in Figures 2 and 3. ${ }^{*} A$ stimulus-compounding test was administered when baseline criteria were met in each phase.

\section{Experimental Design Overview}

In Phase 1 of the present experiment, rats' barpressing was maintained in one discriminative stimulus (e.g., tone) by VI food reinforcement and in another (e.g., light) by FOA. Contingency, reinforcement, and deprivation parameters were chosen that produced comparable rates in tone and in light. (This comparability made these subjects behaviorally similar to those of many single-incentive studies while creating a behavioral referent for future studies that seek to replicate or extend this research.) In the absence of tone and light, extinction was programmed in all phases. After responding was comparable in tone and in light, and ceased in $\overline{\mathrm{T}}+\overline{\mathrm{L}}$, a stimulus-compounding test was administered in which tone, light, and $\mathrm{T}+\mathrm{L}$ were presented in a block-randomized format. The outcome of this test will be compared to the results of the singleincentive studies shown in Figure 1.

Next, extinction was programmed for half the subjects in their FOA component, and for the rest in their VI component, until responding essentially ceased in the presence of these stimuli. In Phase 2, the qualitatively opposite incentive schedule to that operating in Phase 1 was programmed in the stimuli just associated with extinction. Now, half the subjects had VI food reinforcement programmed both in tone and in light (see upper section of Table 1) while, for the rest, FOA was programmed in tone and in light (see lower section of Table 1). Here, where the same incentive maintained comparable barpressing rates in the single stimuli, a stimulus-compounding test was again administered. On the basis of earlier results, substantial additive summation is anticipated if the effects of Phase 1 training are reversible. Phases 3 and 4 were replications of Phases 1 and 2, respectively, making this a withinsubject $\mathrm{ABAB}$ design.

The only difference between Phases 1 and 3 and Phases 2 and 4 was that responding was maintained by the same incentive in tone and in light during Phases 2 and 4, but by qualitatively opposite incentives during Phases 1 and 3 . Therefore, any difference in test results to compound presentations $(T+L)$ over phases could be attributed to the incentive variable, if baseline response rates and patterning in tone and in light are kept comparable within and between phases, and if the effects are reversible.

\section{METHOD}

\section{Subjects}

Twenty male Long-Evans hooded rats served as subjects. Training commenced after they had been food-deprived to approximately $80 \%$ of their ad-lib weights, which ranged from 349 to $430 \mathrm{~g}$. They were housed in individual cages where water was continuously available. Food acquired during a training session was supplemented, shortly after the conclusion of the session, by Tekland rat diet to maintain the rats at their predetermined weights.

\section{Apparatus}

The three similar operant training chambers measured $20 \mathrm{~cm}$ high, $21 \mathrm{~cm}$ long, and $17.5 \mathrm{~cm}$ wide. The front and rear chamber walls were constructed of aluminum. The side walls and ceiling were $0.6-\mathrm{cm}$ white translucent and clear plastic, respectively. The ceiling was vented with 0.6 -cm-diam holes. The chamber floor was composed of $0.3-\mathrm{cm}$-diam stainless steel rods spaced $1.3 \mathrm{~cm}$ between centers. These rods were "floating" with respect to the chambers' side walls, thus eliminating the possibility that feces and urine deposited on the walls could alter shock intensity. A Gerbrands microswitch lever was located on the right side of the front wall $6.9 \mathrm{~cm}$ above the floor. A force equivalent to $.146-.195 \mathrm{~N}$ (15-20 g) was required to operate the lever. A feeder trough was mounted on the extreme left side of the front wall at floor level, and a Gerbrands feeder was employed to deliver 45-mg Noyes rat pellets into it.

The 2000-Hz tone stimulus employed in training and testing was generated by a BRS AA-201 audio oscillator, amplified by a BRS AO-201 amplifier, and presented through an $8-\Omega, 20-\mathrm{cm}$ speaker mounted within an enclosure centered $20.6 \mathrm{~cm}$ above the training chamber. The tone's intensity was approximately $90 \mathrm{~dB}$ measured at the lever with a General Radio 1565-A sound-level meter, scale C, with the microphone parallel to the speaker. With the exhaust fan operating, the ambient noise level was approximately $80 \mathrm{~dB}$. The tone stimulus was practically inaudible outside the attenuation chest.

The light stimulus employed in training and testing was generated by two $15-\mathrm{cm}, 25-\mathrm{W}, 120-\mathrm{V}$ tubular showcase bulbs, each horizontally mounted $1 \mathrm{~cm}$ from the translucent side walls. These two bulbs produced approximately $130.2 \mathrm{~cd} / \mathrm{m}^{2}$, measured with a Honeywell Pentax $1 \% 21^{\circ}$ photometer that was positioned $12.5 \mathrm{~cm}$ from, and directed at, the chamber's side wall.

A shielded 7-W, 120-V nightlight bulb operating at $3 \mathrm{~W}$ served as a houselight that was on continuously. The illumination it produced was too dim to activate the photometer, but it nonetheless allowed the experimenter to just discern the subject within the apparatus. The training chamber and its associated stimuluspresentation devices were enclosed within a sound-attenuation chest described elsewhere (Weiss, 1970). Solid-state programming equipment (BRS) was located in a room adjacent to that housing the training chambers. Constant-current shock was generated by a Lehigh Valley Electronics 1531 shocker and was delivered to the grid floor, manipulandum, and front and rear walls through its associated scrambler.

\section{Procedure}

A sequential outline of the training received by the two groups over the four phases of this experiment is presented in Table 1. In Phase 1, both groups had a VI food-reinforcement schedule operating in one component of a multiple schedule and FOA in another. The Sds for these contingencies were a tone and a light, counterbalanced over contingencies. Periods of tone and light absence $(\overline{\mathrm{T}}+\overline{\mathrm{L}})$, during which no contingency was programmed (EXT), separated the VI and FOA components. Thus, the baseline contingency in Phase 1 was a three-component multiple VI FOA EXT 
schedule. For the group of subjects presented in the upper portion of Table 1, the VI component was unchanged over phases. The FOA component was unchanged for the other group. The five training steps relevant to bringing the rats under criterion stimulus control in Phase 1 are presented below. The training for Phases 1a-4 is described later in this section.

\section{Phase 1: Opposite-Incentive Training}

Step 1 . The rats were initially trained to escape and subsequently to avoid trains of brief, 0.4-0.6-sec, 0.6-0.8-mA shocks by barpressing. An FOA contingency was then instituted wherein responses postponed 0.4-sec shocks by $25 \mathrm{sec}$ (RS $25 \mathrm{sec)}$ while, in the absence of responding, shocks were delivered every $2 \mathrm{sec}$ (SS $2 \mathrm{sec}$ ). Over two to three sessions, the SS interval was gradually increased to $5 \mathrm{sec}$, where it remained for the duration of the experiment. When a rat was exhibiting some proficiency at avoidance under RS $25 \mathrm{sec}$ SS $5 \mathrm{sec}$, to discourage "escape" responses, barpresses emitted during a shock were scheduled to reset the shock-duration timer. (Five subjects that were not progressing in their acquisition of shock avoidance over these initial sessions were eliminated from the study.) Training continued until response rates stabilized and the rats were avoiding at least $75 \%$ of the maximum possible shocks calculated from the RS 25-sec contingency, that is, they were receiving 0.6 shocks $/ \min (60 / 25 \times .25)$ or less. Half the rats had the light continuously on during these sessions and, for the other half, the tone was on.

Step 2. After a rat satisfied the avoidance criterion described above for at least one session, a two-component multiple schedule was instituted. Free-operant avoidance was programmed during the stimulus presented in Step 1 (tone or light) but not when this stimulus was absent. The mean component durations of this multiple FOA EXT schedule were approximately $3.5 \mathrm{~min}$, varied in duration, within and between sessions, within the limits of 2-5 min (with the extinction period extended up to $10 \mathrm{~min}$ for the initial sessions). These sessions were about $4 \mathrm{~h}$ long. Training continued on this multiple schedule until rate in the FOA component was at least 10 times that in the extinction component for four sessions, with an eightsession minimum.

Step 3. All Step 3 training occurred in the presence of the stimulus a rat had not experienced in Steps 1 and 2; for example, if the tone was its Sd for FOA the light was now presented continuously. With the bar removed, the rats were trained to approach the food trough as soon as the feeder operated. When approach and ingestion were prompt, the bar was replaced and the rats were manually trained to press it, through the procedure of successive approximations, on a continuous reinforcement schedule. After approximately $\mathbf{5 0}$ reinforcements, this was shifted to a VI 15-sec schedule that was gradually increased over sessions to VI $60-\mathrm{sec}$. The limits of the VI schedules were $2 \mathrm{sec}$ to 3-4 times the mean value, with intervals sequenced to keep the length of any interval independent of the preceding interval. These sessions ended when approximately 133 pellets had been earned. The subjects received about nine VI food-reinforcement sessions.

Step 4. With the component durations described for Step 2, a rat was run on a multiple VI EXT schedule until it achieved a 10:1 discrimination ratio for four sessions. Approximately 133 pellets were earned per session. The rat was then returned to multiple FOA EXT for 4-6 sessions prior to being placed on its terminal Phase 1 baseline schedule.

Step 5 (final Phase 1 baseline). The three-component final Phase 1 baseline, a multiple VI FOA EXT schedule, was introduced here. When tone was the Sd for the VI contingency, the light was the Sd for FOA. Stimulus-schedule combinations were counterbalanced over subjects. As in previous phases with FOA, at the commencement of an FOA component, the response-shock post- ponement interval was scheduled. In the absence of tone and light $(\overline{\mathrm{T}}+\overline{\mathrm{L}})$, no contingency (extinction) was programmed. The tone and light Sds were always followed by $\bar{T}+\bar{L}$, whereas tone or light were equally likely to follow $\overline{\mathrm{T}}+\overline{\mathrm{L}}$, with the restriction that an Sd be presented no more than three times in succession. Component durations varied within the limits of 1.5 and $5 \mathrm{~min}$. Unearned food reinforcers in any component were not carried to the next VI component. Sessions were about $4 \mathrm{~h}$ in duration.

Training criteria. Phase 1 baseline training continued on multiple VI FOA EXT until, for at least three consecutive sessions, after a 30-min warmup, (1) mean response rates in the VI and FOA components were within 1 response/min of each other, (2) rates in tone and light Sds were at least 10 times the rates in $\bar{T}+\bar{L}$, (3) shock rates in FOA were 0.6 per min or less, and (4) responding commenced prior to a shock prompt in at least $75 \%$ of the FOA components. To satisfy these criteria, especially Criterion 1 , it was necessary to manipulate VI values, food deprivation, RS intervals, and/or shock intensities. (Many of these training parameters for each subject in Phases 1 and 2 are included in Figures 2 and 3, which will be introduced in the Results section.) When a subject satisfied these criteria, a stimulus-compounding test was administered. (Six subjects were eliminated at this stage of training because we could not make their VI and FOA rates comparable.) Stimulus-compounding test. Tone, light, and $\mathrm{T}+\mathrm{L}$ were presented in each of 12 block-randomized replications. $\bar{T}+\bar{L}$ separated these stimuli. All presentations were $1 \mathrm{~min}$ in duration, making the test 72 min long. A representative test block could consist of the following sequence of stimuli: tone, $\bar{T}+\bar{L}, T+L, \bar{T}+\bar{L}$, light, $\bar{T}+$ $\overline{\mathrm{L}}$. The animals were given approximately $30 \mathrm{~min}$ of the baseline training schedule prior to testing, but all contingencies were discontinued during the test.

\section{Phase 1a (2a and 3a)}

In preparation for the contingency reversal of Phase 2, one of the contingencies-VI or FOA-was discontinued during its previously correlated stimulus, changing the schedule from a multiple VI FOA EXT to multiple VI EXT EXT or multiple FOA EXT EXT. With the exception that the newly programmed extinction component was occasionally extended to 10 min during the initial sessions of Phase la, component and session durations in this and subsequent phases were kept comparable to those of Phase 1. Training continued until, for three consecutive sessions, rates in VI or FOA schedule components were at least $\mathbf{1 0}$ times the rate in either extinction component, FOA responding commenced prior to shock prompt in at least $75 \%$ of the components, and fewer than 0.6 shocks/min were received. Then the Phase 2 baseline was introduced. (To ensure that all contingency reversals for a subject were instituted in comparable behavioral contexts, the subjects were also returned to multiple VI EXT EXT or multiple FOA EXT EXT prior to the introduction of Phase 3 and Phase 4 baselines. As indicated in Table 1, for each subject only one Sd-tone or lightwas subjected to contingency reversals over phases.) Subject 393 was lost in this phase due to an equipment malfunction, leaving 8 subjects that completed the experiment.

\section{Phase 2: Similar-Incentive Training}

In this phase, the same class of reinforcer (positive or negative) maintained responding in tone and light, whereas $\bar{T}+\bar{L}$ continued to signal extinction. Thus, half the subjects were on a multiple VI VI EXT schedule and the other half were on a multiple FOA FOA EXT schedule. These schedules were instituted by maintaining responding in the component (tone or light) subjected to extinction in Phase 1a, but with the class of reinforcer opposite to that employed in Phase 1 with that Sd (see Table 1). The subjects were trained on these similar-incentive multiple schedules until they satis- 
fied the discrimination criteria described in Phase 1, Step 5. They then received a stimulus-compounding test like that described for Phase 1.

\section{Phase 3: Opposite-Incentive Training}

The training and testing in this phase were like that described for Phase 1, Step 5.

\section{Phase 4: Similar-Incentive Training}

The training and testing in this phase were like that described for Phase 2 .

\section{RESULTS}

\section{Performance on the Training Baselines}

Figures 2 and 3 present individual cumulative records from criterion baseline training sessions of Phases 1 and 2 . The records of subjects receiving the training outlined in the top portion of Table 1 (VI unchanged) are presented in Figure 2; the records of subjects receiving the training outlined in the bottom portion of Table 1 (FOA unchanged) are presented in Figure 3. The parameters of the individual training schedules as well as the mean response rates in each schedule component over criterion sessions of all four phases are also presented in these figures. Phase 1 VI and FOA mean criterion rates in these schedule components were almost identical for most subjects, with no difference greater than 1 response/min. However, similar rates can be produced by different patterns of response emission over time.

Close examination of the "grain" revealed in the cumulative records permits an evaluation of behavioral comparability in the VI and FOA components that takes response patterning and behavioral transitions into account. The Phase 1 records, in the left frames of Figures 2 and 3, of Subjects 394, 400, 415, and 430 reveal grain with similar characteristics in the VI and FOA components. For Subject 472 , there were many instances in which the grain of the VI and FOA components were indistinguishable, but some FOA periods had clearly smoother grain than did any VI period. For Subjects 392 and 464 , the FOA-component grain was consistently smoother than that of their VI components. These characteristics of response patterning over schedules were unrelated to stimulus-schedule combination. Behavioral transitions upon schedule-component change were abrupt for all subjects, with $\overline{\mathrm{T}}+\overline{\mathrm{L}}$ consistently controlling a negligible level of responding. The Phase 1 training goals of response comparability over appetitive and aversive schedules were achieved in most subjects.

The frames to the right in Figures 2 and 3 present rates and patterns of behavior generated in Phase 2, in which the same schedule-VI (Figure 2) or FOA (Figure 3)was programmed in tone and in light. As one would expect, mean rates as well as response patterning are comparable in tone and light under these conditions. The degree of behavioral control achieved in Phase $1 \mathrm{might}$ be appreciated if one notes that the 0.4 -response $/ \mathrm{min}$ average rate difference between the VI and FOA Sds in
Phase 1 (in which training parameters were manipulated to produce rate equality) was only one third of the average rate difference between Sds (1.2 responses/min) obtained in Phase 2 (in which the same contingency was programmed in each $\mathrm{Sd}$ ).

In the transition from multiple VI FOA EXT to multiple VI VI EXT, the response rate emitted by Subjects 394 and 472 doubled, that of Subject $\mathbf{4 7 7}$ changed very little, and that of Subject $\mathbf{4 0 0}$ halved. In the transition from multiple VI FOA EXT to multiple FOA FOA EXT, the rates remained essentially similar over phases for all subjects. Thus, nothing systematic occurred during these transitions for either group, although there was more variability in the transition among those subjects that were changed from FOA to VI (Figure 2) than among those that were changed from VI to FOA (Figure 3) in Phase 2.

Figures 2 and 3 also contain the mean criterion rates for each subject in Phases 3 and 4 of this study (see the upper left corner of each frame). The rate comparabilities achieved between Sds in Phases 1 and 2 were replicated in Phases 3 and 4, respectively. Figure 4 presents the mean rates in the VI and FOA components over Phases 1-4. The subjects for which VI remained unchanged over phases are shown in Frame a, and the subjects for which FOA remained unchanged over phases are shown in Frame b. A treatments (phases) $\times$ subjects ANOVA (Lindquist, 1953) indicated that rates were comparable in an Sd over phases whether responding was (1) always maintained by VI (food) $[F(6,18)=0.94, p>.2]$, (2) always maintained by FOA (shock avoidance) $[F(6,18)=1.19, p>.2]$, or (3) maintained by different incentives over phases $[F(3,9)$ $=0.67, p>.2$ (Figure $4 a$ ), and $F(3,9)=0.64, p>.2$ (Figure 4b)]. (For the ANOVAs performed in 1 and 2, above, VI or FOA rates, respectively, from Phases 1a, 2a, and $3 a$ were included.)

\section{Stimulus-Compounding Tests}

Opposite-incentive training. The mean percentage of total stimulus-compounding test responses emitted to the FOA Sd, the VI Sd, and T+L in Phases 1 and 3 is presented in the left frames of Figure 5. Individual test data presented in Table 2 reveal that the $T+L$ rate emitted by a subject was usually between its VI and FOA Sd rates. In Phase 1 , mean rates to the VI Sd, the FOA Sd, and $\mathrm{T}+\mathrm{L}$ were almost identical, with these rates also close in Phase 3.

On average, in Phase 1 tests, a comparable number of responses was controlled by the FOA Sd whether it was tone or light $[t(7)=0.60, p>.5]$, and the same was true for the VI Sd $[t(7)=1.24, p>.2]$. Therefore, all subjects were combined for a treatments (FOA Sd, VI Sd, $\mathrm{T}+\mathrm{L}) \times$ subjects ANOVA, which yielded an $F(2,16)=$ 0.01 . Response rates overall were the same to the VI Sd, the FOA Sd, and $\mathrm{T}+\mathrm{L}$.

The Phase 1 test results were completely replicated when the subjects were returned to their multiple VI FOA EXT baselines in Phase 3. The subjects were again combined for the ANOVA since tone- and light-FOA Sds con- 


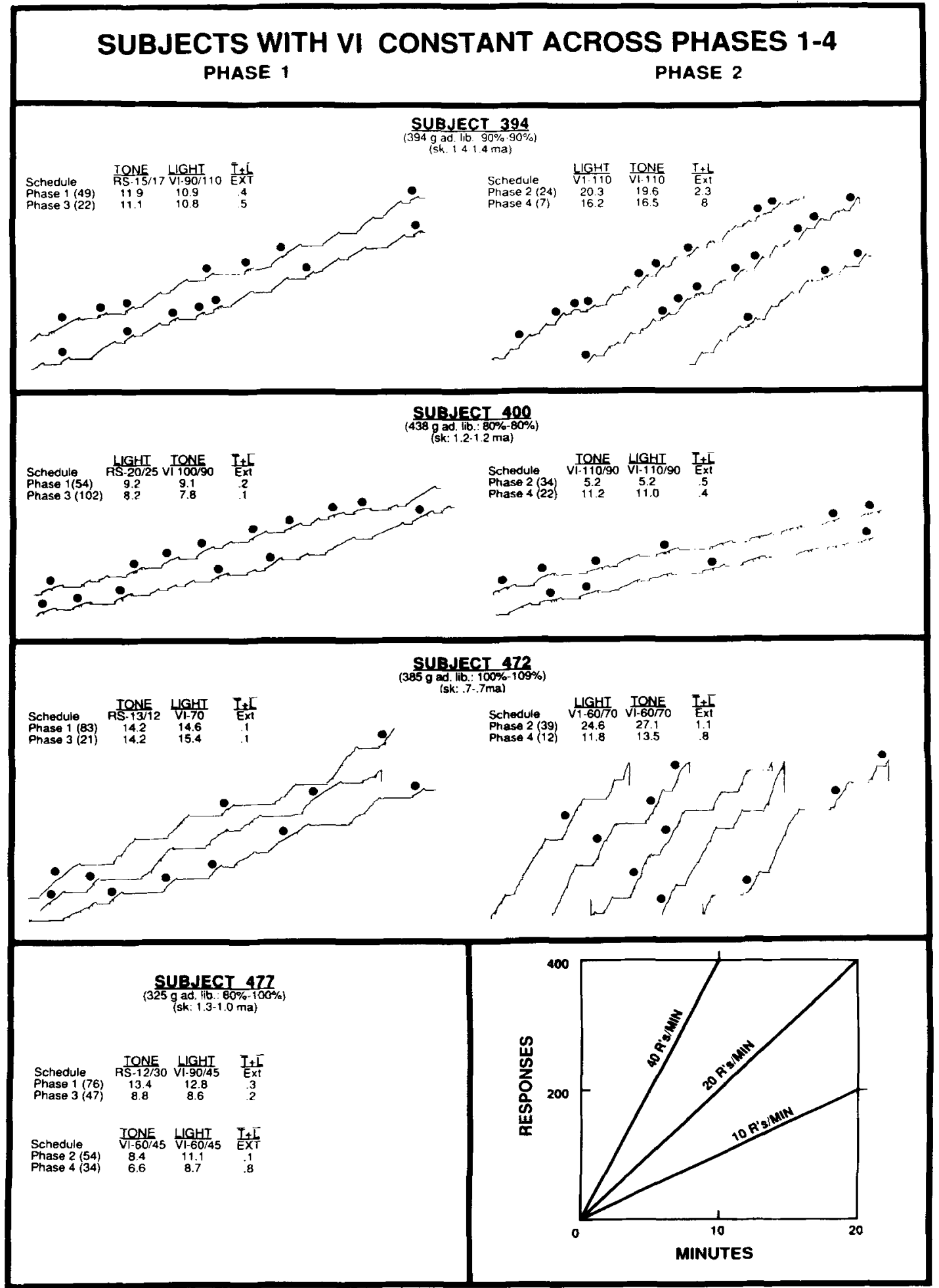

Figure 2. A cumulative record segment of approximately 1.5-h duration from a criterion session of Phase 1 (left frames) and Phase 2 (right frames) for subjects for which VI remained unchanged over training phases. When the response pen was in the upper register, a tone (filled circles) or light component, as indicated, was in effect. Slash marks signify a food or shock presentation. The response pen was in the lower register when neither tone nor light were present (extinction). A subject's ad-lib weight, as well as its running weight and the shock intensity range over Phases 1-4, are given directly below its number. A repeated number indicates no change in that parameter over phases. Indicated in the upper left of each frame are the subject's baseline training contingencies programmed in each stimulus plus its criterion response rates in Phases 1 and 3 (left frames) and Phases 2 and 4 (right frames). Two numbers $(x / y)$ describing a schedule indicate a modification over phases. (The cumulative records of Subject 477 were not available.) 


\section{SUBJECTS WITH FOA CONSTANT ACROSS PHASES 1-4}

PHASE 1

PHASE 2

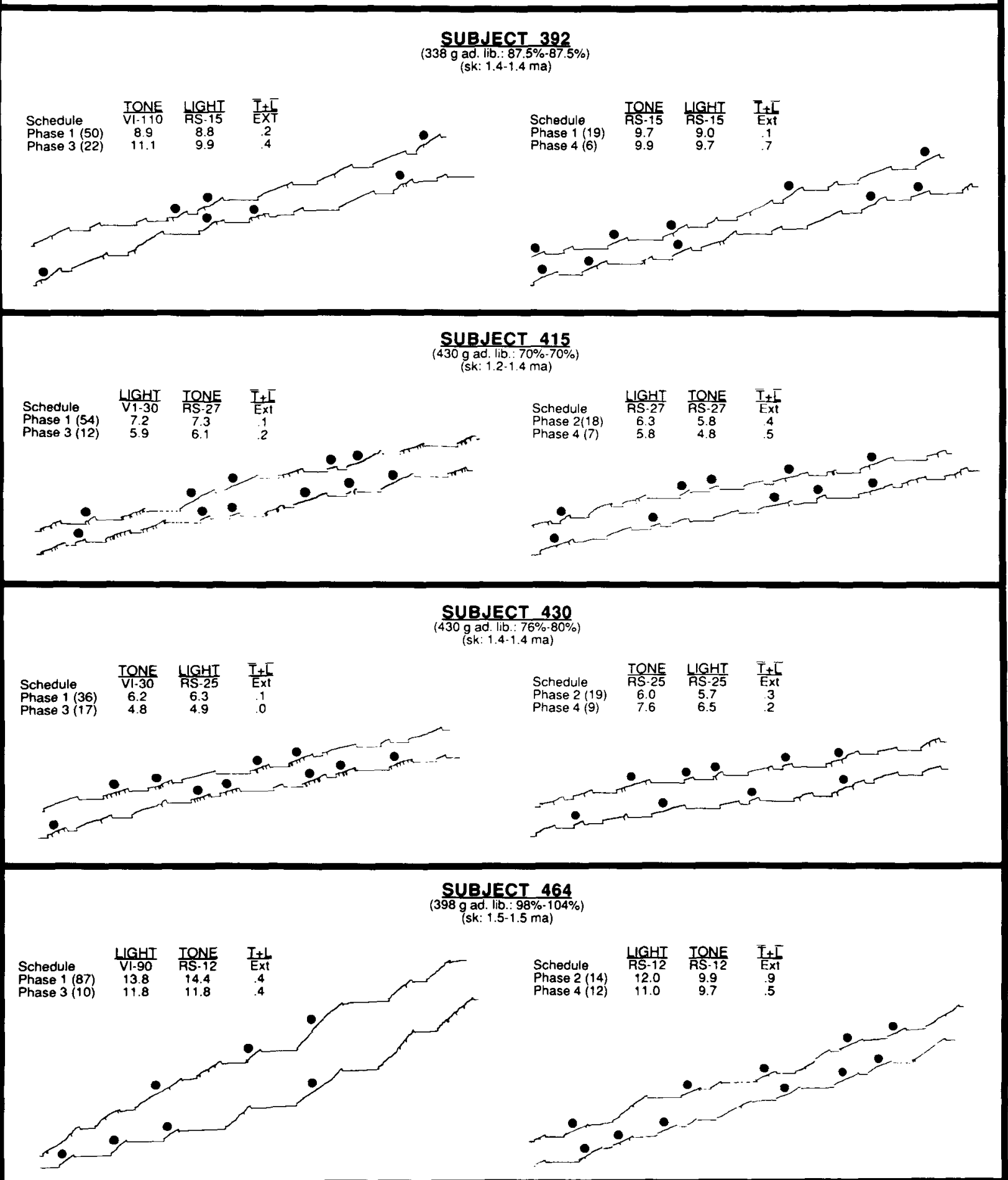

Figure 3. A cumulative record segment of approximately 1.5-h duration from a criterion session of Phase 1 (left frames) and Phase 2 (right frames) for subjects for which FOA remained the unchanged component over training phases. See Figure 2 caption for explanation. 
trolled similar rates $[t(6)=0.59, p>.6]$, as did both VI Sds $[t(6)=0.39, p>$.7]. An $F(2,14)=0.26$ substantiated what was clear from Figure 5 and the individual data of Table 2. In the Phase 3 test, the VI Sd, the FOA $\mathrm{Sd}$, and $\mathrm{T}+\mathrm{L}$ again controlled comparable response rates. Complete within-subject replication was achieved over Phases 1 and 3.

Similar-incentive training. The mean percentage of stimulus-compounding test responses emitted to tone, light, and $T+L$ in Phases 2 and 4 (in which the same reinforcer maintained responding in tone and in light) is presented in the right frames of Figure 5 . Here, on average, $T+L$ controlled about double the rate of the single stimuli. These results are markedly different from those produced in Phases 1 and 3 (in which different classes of reinforcer operated in tone and in light). Table 3 shows

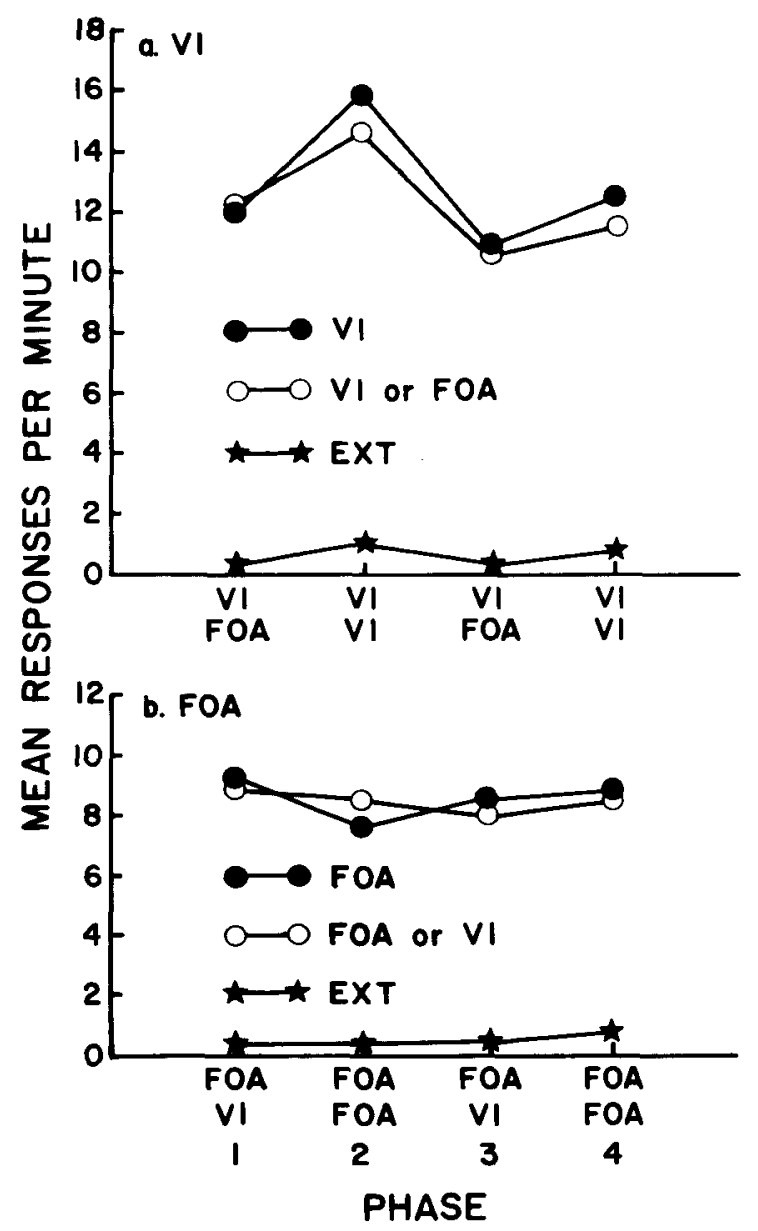

Figure 4. Mean rates to variable interval (VD) and free-operant avoidance (FOA) discriminative stimuli, as well as extinctionassociated absence of tone and light $(\overline{\mathbf{T}}+\overline{\mathrm{L}})$, during baseline criterion sessions preceding the stimulus-compounding tests of Phases 1-4. The subjects whose VI components were maintained over all phases are presented in the upper frame, and those whose FOA components remained unchanged over all phases are presented in the lower frame. Baseline criterion rates for individual subjects from which these means were derived can be found in Figures 2 and 3.

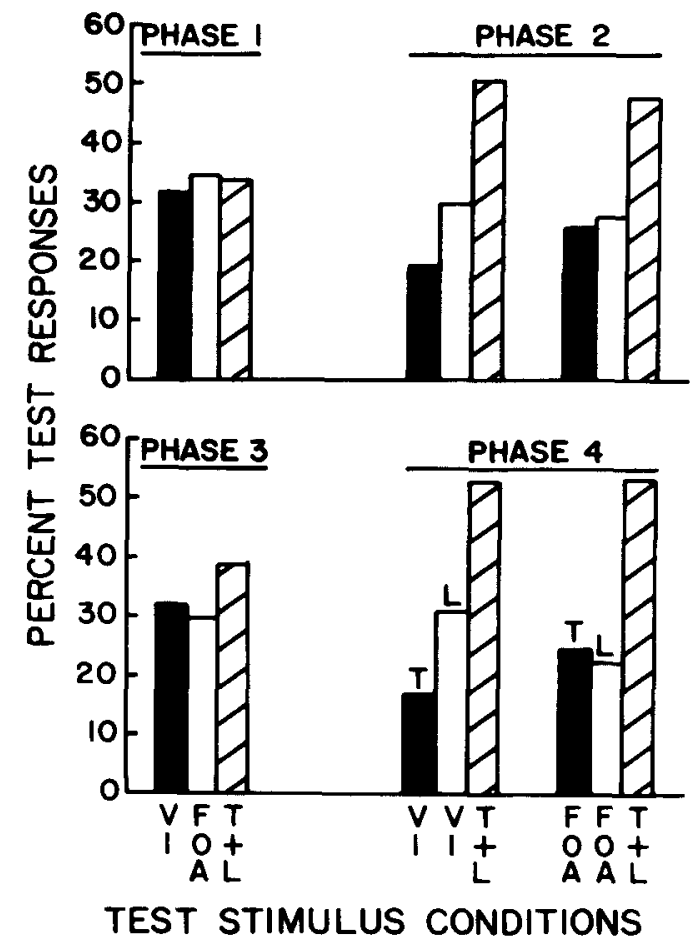

Figure 5. Mean percentage of stimulus-compounding test responses emitted to the FOA Sd, the VI Sd, and T $+L$ in Phases 1 and 3 (left sets of bars) and mean percentage of test responses emitted to each VI Sd and $T+L$, as well as to each FOA Sd and $T+L$, in Phases 2 and 4 (right sets of bars). These mean percentages were calculated by converting the outputs of each subject to each test condition to a percentage of that subject's total test responses, and then averaging each condition over subjects. The test performance of each subject from which these percentages were calculated can be found in Tables 2 and 3.

that $\mathrm{T}+\mathrm{L}$ controlled more responding than did tone or light for all subjects in both phases, with the means of both the VI- and the FOA-trained animals revealing what appears to be a simple additivity between rates to the single- and compound-test conditions.

In Phase 2, a treatments (tone, light, $\mathrm{T}+\mathrm{L}$ ) $\times$ subjects ANOVA of the stimulus-compounding test results for FOA-trained subjects produced an $F(2,6)=13.12, p<$ .01 . Rates to tone and light were equal $(t=0)$, whereas significantly more responses were emitted to $\mathrm{T}+\mathrm{L}$ than to tone $[t(6)=4.44, p<.01]$ or light $[t(6)=4.44, p<$ $.01]$. For the VI-trained subjects, $F(2,6)=26.13, p<$ .005 . More responses were emitted to light than to tone $[t(6)=2.48, p<.05]$, whereas $\mathrm{T}+\mathrm{L}$ controlled significantly more responses than did tone $[t(6)=7.12$, $p<.01]$ or light $[t(6)=4.64, p<.01]$. (The treatments $X$ subjects interaction term supplied the degrees of freedom for the $t$ tests performed after a significant ANOVA; Lindquist, 1953.)

Phase 4 tests replicated those of Phase 2. The test administered to FOA-trained subjects yielded an $F(2,6)=$ $21.90, p<.005$. Rates to tone and light were comparable $[t(6)=0.38, p>.7]$, whereas rates to $\mathrm{T}+\mathrm{L}$ were 
Table 2

Stimulus-Compounding Test Results (Total Responses) After Opposite-Incentive Training

\begin{tabular}{llllllllllll}
\hline & \multicolumn{10}{c}{ Subject } \\
\cline { 2 - 3 } & 392 & 393 & 394 & 400 & 415 & 430 & 464 & 472 & 477 & Mean \\
\hline \multicolumn{8}{c}{ Phase 1} \\
FOA & 65 & $57^{*}$ & 125 & 82 & $50^{*}$ & 80 & $113^{*}$ & $174^{*}$ & $132 *$ & 97.6 \\
VI & $35 *$ & 54 & $120^{*}$ & $98^{*}$ & 53 & $34^{*}$ & 181 & 122 & 188 & 98.3 \\
T+L & 42 & 49 & 137 & 92 & 82 & 58 & 123 & 161 & 149 & 99.2 \\
\multicolumn{8}{c}{ Phase 3} \\
FOA & 64 & & 114 & 57 & 20 & 24 & 140 & 171 & 28 & 77.3 \\
VI & 142 & & 118 & 78 & 13 & 15 & 133 & 83 & 67 & 81.1 \\
T+L & 59 & & 153 & 74 & 39 & 41 & 132 & 142 & 57 & 87.1 \\
\hline
\end{tabular}

Note-FOA $=$ discriminative stimulus correlated with free-operant avoidance in training; VI = discriminative stimulus correlated with variable-interval food reinforcement in training; $T+L=$ tone plus light (simultaneous presentation of VI and FOA discriminative stimuli). Stimulus-compounding test was performed in extinction. *Tone.

significantly higher than were those to tone $[t(6)=5.82$, $p<.01]$ or light $[t(6)=5.44, p<.01]$. The results of the VI-trained subjects also proved significant $[F(2,6)=$ $15.62, p<.005]$. Here again, significantly more responses were emitted to $\mathrm{T}+\mathrm{L}$ than to tone $[t(6)=5.46$, $p<.01]$ or light $[t(6)=3.24, p<.02]$, whereas the superiority of responding to light over tone only approached significance $[t(6)=2.20, .1>p>.05]$.

Response rates were comparable in tone and in light in all training phases of the experiment in which the contingencies were operating. Nevertheless, a majority of the subjects did not emit a comparable number of responses to these single stimuli during the tests that were administered in extinction. For example, in Phase 2 (Table 3), 5 of the 8 subjects emitted at least 1.4 times as many responses in one of the single stimuli as in the other, and this was true for a comparable proportion (5/9) of the Phase 1 subjects (Table 2). In Phase 1, this differential resistance to extinction was unrelated to stimulus modal-

Table 3

Stimulus-Compounding Test Results (Total Responses) After Similar-Incentive Training

\begin{tabular}{|c|c|c|c|c|c|c|}
\hline \multirow[b]{2}{*}{ Subject } & \multicolumn{3}{|c|}{ Phase 2} & \multicolumn{3}{|c|}{ Phase 4} \\
\hline & Tone & Light & $\mathrm{T}+\mathrm{L}$ & Tone & Light & $T+L$ \\
\hline \multicolumn{7}{|c|}{ Trained with VI in Tone and in Light } \\
\hline 394 & $155^{*}$ & 224 & 371 & 130 & 149 & 307 \\
\hline 400 & $102 *$ & 121 & 181 & 177 & 180 & 356 \\
\hline 472 & 192 & $292^{*}$ & 436 & 49 & 173 & 217 \\
\hline 477 & 45 & $116^{*}$ & 250 & 16 & 60 & 108 \\
\hline Mean & 123.5 & 188.3 & 309.5 & 93.0 & 155.5 & 247.0 \\
\hline \multicolumn{7}{|c|}{ Trained with FOA in Tone and in Light } \\
\hline 392 & 62 & $84^{*}$ & 118 & 59 & 83 & 134 \\
\hline 415 & $29^{*}$ & 30 & 47 & 16 & 7 & 37 \\
\hline 430 & 43 & $25^{*}$ & 99 & 36 & 33 & 91 \\
\hline 464 & $57^{*}$ & 52 & 105 & 54 & 54 & 89 \\
\hline Mean & 47.8 & 47.8 & 92.3 & 41.3 & 44.3 & 87.8 \\
\hline
\end{tabular}

Note-VI $=$ variable-interval food schedule; FOA $=$ free-operant avoidance; $\mathrm{T}+\mathrm{L}=$ simultaneous presentation of tone and light. Stimuluscompounding test was performed in extinction. *Stimulus with unchanged contingency over all phases of experiment. ity or incentive. In Phase 2 , it was unrelated to modality for the FOA subjects, whereas the VI subjects emitted more responses to the light than to the tone.

All of the Phase 2 (similar-incentive) subjects referred to in the preceding paragraph produced strong additive summation to $T+L$. In comparison, responding to $T+L$ was intermediate to that controlled by the single stimuli for the Phase 1 (opposite-incentive) subjects described above. This means that a differential resistance to extinction by the single stimuli in testing was unrelated to test outcome. Rather, the determining factor was the opposite versus similar incentive training experienced in the training phase preceding the stimulus-compounding test.

\section{DISCUSSION}

In Phases 1 and 3 of the present experiment, a stable rate of barpressing was maintained in one Sd by food, whereas similar barpressing was maintained in another Sd by shock avoidance. This comparability was revealed in multiple ways. Average overall rates in one Sd were generally within one-half response per minute of the rates in the other Sd during criterion sessions for all subjects. However, even more informative in this regard were the patterns of barpressing over time produced by 5 of the 7 subjects for which cumulative records were available. The "grain" of their cumulative record segments generated during a VI Sd were generally indistinguishable from that generated by their barpresses emitted during an FOA Sd. This operant response comparability in the two Sds minimized the likelihood of competing peripheral operants contributing to the stimulus-compounding test outcomes and created an operant baseline behaviorally indistinguishable from those used to generate the incentive function presented in Figure 1, in which the same class of schedule (appetitive) maintained responding in the tone and light Sds. In addition, since all tests of the present experiment (and those of Figure 1) were performed in extinction, the influence of unconditioned consummatory responses on test results should also have been minimized.

All groups represented in Figure 1 were behaviorally comparable, barpressing in tone and in light, and ceasing barpressing in $\overline{\mathrm{T}}+\overline{\mathrm{L}}$. It was the conditioned incentive value established to these stimuli through their being associated with an increase, no change, or a decrease in reinforcement, relative to $\overline{\mathrm{T}}+\overline{\mathrm{L}}$, that distinguished the groups. Since the classical $\mathbf{S}-\mathrm{S}^{\mathbf{r}}$ contingency is embedded in the operant $S d-R-S^{r}$ contingency, "the general nature of the influence of a conditioned incentive stimulus on behavior should be essentially the same whether its incentive properties are acquired in the classical or operant procedure" (Bindra, 1972, p. 472). According to this analysis, the Sds in Figure 1 were appetitive excitors (Point A,B), neutral (Point B,C), or appetitive inhibitors (Point D).

At Point B,C in Figure 1, at which tone and light each controlled an increase in response but conditioned incentive was not contributing to the test outcome, moderate 
additive summation is indicated. If interacting motive states had merely "neutralized" each other in Phases 1 and 3 of the present experiment, results of a comparable nature would be anticipated. However, in Phases 1 and 3 , not even modest additive summation occurred in testing. Test rates to $\mathrm{T}+\mathrm{L}$, tone, and light were equivalent, just as they were for the subjects represented by Point $D$ in Figure 1, in which the training contingency made both tone and light conditioned inhibitors. Taken literally, this comparison suggests that simultaneously presenting a conditioned appetitive excitor and a conditioned aversive excitor is in some ways motivationally comparable to presenting two conditioned inhibitors of the same incentive class. Although this comparability must be viewed cautiously and would probably be influenced by contingency parameters, we feel safe in concluding that appetitiveaversive interactions actively reduce motive states through reciprocal inhibition that is subtractive in the same manner as conditioned inhibition. This supports, while in a manner quantifying, Dickinson and Dearing's (1979) conclusion that "appetitive-aversive interactions are of an inhibitory or antagonistic nature, with a conditioned excitor of one affective value having an inhibitory effect in ... summation ... tests of responses established with a reinforcer of the opposite affective polarity" (p. 207).

One could argue that the overall rate equivalence to $\mathrm{T}+\mathrm{L}$, tone, and light in the present experiment is a product of appetitive and aversive incentive systems not interacting. However, that position is hardly tenable in light of the vast conditioned suppression literature (Davis, 1968; Millenson \& de Villiers, 1972) and the findings showing that the effects of superimposing shock-associated stimuli on an operant baseline depend on whether the performance is maintained by food or shock avoidance (Herrnstein \& Sidman, 1958; Overmier et al., 1971).

Unambiguously attributing suppressed behavior to the reciprocal inhibition of incompatible motive states, rather than to the competition of peripheral operants or respondents, has been exceptionally difficult in the investigation of appetitive-aversive interactions. However, our foregoing comparison of appetitive-aversive interactions and conditioned inhibition has been supported by the retardation of acquisition in classical conditioning (Scavio, 1974) and superconditioning experiments (Dickinson, 1977; Fowler, Fago, Domber, \& Hochhauser, 1973), two designs in which an interpretation in terms of competing peripheral operants is not tenable. The present study is the first to document this reciprocal inhibition in an instrumental experiment in which the influence of competing peripheral operants on the incentive interaction was minimized (although one can never be sure it has been completely eliminated) through training contingencies (see Figures 2 and 3 ).

The effects of appetitive-aversive interactions on the results of stimulus compounding in Phases 1 and 3 of the present experiment have been compared to the effects produced by conditioned inhibitors in an appetitive situation in which barpressing increased in tone and in light while these stimuli signaled a reduction to zero in food. Assuming that the motivational processes operating in these situations are general in nature, then tone, light, and $T+L$ should also control comparable rates in testing after the animals were trained on the aversive analogue of that chain VI DRO baseline. That baseline's aversive analogue would have rats barpressing to avoid shock in a tone and a light that was less "feared" than the condition that separated them $(\overline{\mathrm{T}}+\overline{\mathrm{L}})$, in which they did not barpress.

Weiss (1976, Experiment 3) worked with such an aversive analogue schedule. His rats effectively barpressed to postpone shock for $25 \mathrm{sec}$ in tone and in light, whereas in $\overline{\mathbf{T}}+\overline{\mathrm{L}}$ they received noncontingent shock, and barpresses were intermittently punished. On this schedule, barpressing increased in tone and in light while these stimuli became less "feared" than $\bar{T}+\bar{L}$, since an avoidance schedule over which an organism has some control is preferred to unpredictable and unavoidable shock (Badia \& Culbertson, 1972; Knapp, Kause, \& Perkins, 1959). When these stimuli, which maintained FOA but were conditioned inhibitors of fear, were compounded, tone, light, and $\mathrm{T}+\mathrm{L}$ controlled similar rates. These results are the same as those from the comparable appetitive situation of Figure 1 (Point D) and those produced by the appetitive-aversive interactions in Phases 1 and 3 of the current experiment. There appears to be motivational equivalence of reciprocal inhibitors and multiple conditioned inhibitors, whether the latter are from appetitive or aversive situations.

In Phases 1 and 3 of the present experiment, appetitiveaversive interactions were studied in a situation designed to minimize the influence of competing peripheral operants on test outcomes. Overmier and Schwarzkopf (1974) performed a related experiment but reported outcomes they interpreted as inconsistent with the notion that appetitive-aversive interactions produce reciprocal inhibition. Theirs was one of the few studies to find response enhancement when reciprocal inhibition would be expected from interacting motive states. A detailed analysis of their procedure might shed some light on the reasons for the apparent inconsistency between that study and the present experiment.

In Phase 1 of their study, Overmier and Schwarzkopf (1974) used a discrete-trials procedure to train dogs to hurdle jump for food in $S+$. Jumping was eliminated to $S-$ and during intertrial intervals through extinction. In Phase 2, hurdle jumping was maintained by FOA, a reinforcer qualitatively opposite to that used to maintain jumping in Phase 1. The other group was trained symmetrically, receiving discrete-trial avoidance training in Phase 1 with hurdle jumping maintained by free-operant food reinforcement in Phase 2 . In both groups, when the $S+$ was presented while hurdle jumping was being sustained by the Phase 2 baseline contingency, responding was facilitated for all animals. Overmier and Schwarzkopf concluded that their findings "cast doubt on explanations of conditioned suppression outcomes that appeal solely to incompatible [appetitive-aversive] motivational states 
within the organism" (p. 42), while demonstrating that "additive response summation apparently is not restricted to Sds associated with hedonically similar reinforcers" (p. 51).

Unfortunately, or fortunately for general theories of motivated behavior that postulate antagonism between hedonic classes (see Dickinson \& Pearce, 1977), Overmier and Schwarzkopf's (1974) data cannot be unambiguously interpreted this way given their training and test procedures. Overmier and Schwarzkopf only monitored the effects of superimposing the Phase $1 \mathrm{~S}+$ on the Phase 2 baselines. Rates in $S+$ during Phases 1 and 2 were not compared. In fact, response rates in $\mathrm{S}+$ during Phase 1 were not even supplied. However, it is likely that S+ rates in Phase 1 were appreciably higher than Phase 2 baseline rates. A variable-ratio schedule, which tends to produce high rates, was programmed in $\mathrm{S}+$ in Phase 1 , whereas Phase 2 rates were maintained by VI food reinforcement or $30 \mathrm{sec}$ of shock postponement-contingencies that maintain low to moderate rates. This would mean that even though $\mathrm{S}+$ increased rates over baseline in Phase 2 "summation" tests of the Overmier and Schwarzkopf study, these Phase $2 \mathrm{~S}+$ rates could simultaneously have been lower than Phase $1 \mathrm{~S}+$ rates. If they were lower, this reduction could be interpreted "centrally" as a product of the incompatible motivational states operating in testing or "peripherally" as the product of mixing higher $\mathrm{S}+$ rates with lower Phase 2 baseline rates. The only outcome of the Overmier and Schwarzkopf study that would support their interpretation would have rates to $S+$ on the Phase 2 tests higher than rates to $S+$ in Phase 1 , a result inconsistent with previous research (Herrnstein \& Sidman, 1958; Overmier et al., 1971). From this we conclude that although the results of the Overmier and Schwarzkopf study appear inconsistent with those of the present experiment, they would probably support appetitive-aversive interaction theory if all the data were available and relevant comparisons were made. ${ }^{1}$

The rates to the purportedly facilitative Sds alone (i.e., independent of their rate when superimposed on the affectively opposite test baseline) would also be germane in interpreting the results of Linder and Ehrman (in Overmier \& Lawry, 1979, pp. 34-41), which were presented as supporting those of Overmier and Schwarzkopf (1974). In these studies also, "compound" rates that are higher than those to the facilitative Sd presented alone would be necessary to demonstrate that "mediational stimuli, when given the opportunity to become associated with the target response, do so and may predominate over opposing motivational effects arising from the interaction of two antagonistic affective states"' (Overmier \& Lawry, 1979, p. 39).

The foregoing analysis of the Overmier and Schwarzkopf (1974) study was not meant to imply that a discriminative stimulus does not acquire "response cuing" as well as "response energization" functions. In fact, the failure of two Sds that signaled the absence of food, and thereby were affectively conditioned inhibitors, to produce response suppression (Figure 1, Point D) was attributed, in the introduction, to the increase in responding that these Sds also controlled. Moreover, Overmier and Lawry (1979) and Weiss (1978) both present convincing evidence that these functions can be independently manipulated in appetitive as well as aversive situations. We are only suggesting that Overmier and Schwarzkopf did not necessarily demonstrate additive summation when they "compounded" Sds associated with hedonically opposite reinforcers. Their results are probably consistent with those of Phases 1 and 3 of the present experiment and motivational theories predicting that the interaction of appetitive and aversive excitors produces reciprocal inhibition.

In Phases 2 and 4, in which the same incentive maintained responding in tone and in light, in testing $\mathrm{T}+\mathrm{L}$ controlled more than double the response rate of tone or light alone-a clear example of additive summation. This was the case whether responding in tone and in light was maintained by food or by shock avoidance. This replicates many previous findings of single-incentive stimuluscompounding studies (Emurian \& Weiss, 1972; Meltzer \& Masaki, 1972; Miller \& Ackley, 1970; Weiss, 1964, $1971,1976)$ while showing that the stimulus control established to create the appetitive-aversive interaction in Phases 1 and 3 was reversible. It is likely, however, that the contingency reversals over phases could have reduced the magnitude of the additive effect from what it would have been if the subjects had been trained on only the Phase 2 similar-incentive baseline, as they were for the studies represented by Point A,B in Figure 1.

\section{CONCLUSION}

Investigations of affective interactions are of general importance for understanding the functional organization of motivational and reinforcement mechanisms. This has been well documented by Dickinson and Dearing (1979) and Dickinson and Pearce (1977) in their integrative reviews of the theory and research in that area. On the basis of the research relevant to appetitive-aversive interactions, they proposed, in essential agreement with Konorski's (1967) position, that appetitive and aversive incentives lie along a common dimension but run in opposite directions such that (1) an excitatory appetitive incentive is equivalent to an inhibitory aversive incentive, (2) an excitatory aversive incentive is equivalent to an inhibitory appetitive incentive, and (3) a combination of excitatory appetitive and aversive incentives are reciprocally inhibiting. This is an exceptionally parsimonious, ultimately psychological, theory of motivation. It is based on hedonics, with the behaving organism evaluating different reinforcement situations as a comparator.

The current research was concerned with the third proposition, and directly measured the appetitiveaversive interaction in an experimental paradigm in which a demonstrably comparable peripheral operant (barpressing) was involved in earning food and avoiding shock. 
This was evident in the performance during training (described in Figures 2 and 3). In addition, with the summation tests performed in extinction, stimuli that could produce behaviors that could potentially interfere with the measured operant, such as magazine clicks and shocks, were not presented. Of course, one can never conclude decisively that all potential competing operants or respondents were eliminated in these situations, but this experiment appears to approximate that objective more closely than others reported to date investigating these interactions.

Were we just fortunate in Phases 1 and 3 in choosing appetitive and aversive reinforcement parameters that generated a reciprocal inhibition that evenly counteracted the discriminative response control of the Sds? We think not. Within rather wide limits, as long as the appetitive and aversive contingency parameters produce similar rates and patterns of response in the single Sds, it is anticipated that $\mathrm{T}+\mathrm{L}$, tone, and light would control, overall, comparable rates on a compounding test. We predict this because rates to the single Sds would vary with reinforcement magnitude that also influences the level of conditioned excitation.

With the operant as a controlled factor over experimental phases in the present experiment, reciprocal inhibition was revealed when opposing motive states were activated, whereas additive summation was produced when excitors of the same incentive class were compounded. When the results from the present incentive interaction study were compared with those from the network of related stimulus-compounding studies investigating the influence of appetitive or aversive incentive variables on behavior, startling equivalences were revealed. It appears that the reciprocal inhibition resulting from simultaneously presenting conditioned appetitive and aversive excitors is motivationally comparable in these situations to presenting conditioned inhibitors of the same incentive class.

\section{REFERENCES}

BAdiA, P., \& Culbertson, S. (1972). The relative aversiveness of signalled vs. unsignalled escapable and inescapable shock. Journal of the Experimental Analysis of Behavior, 17, 463-471.

BINDRA, D. A. (1972). A unified account of classical conditioning and operant training. In A. M. Black \& W. F. Prokasy (Eds.), Classical conditioning: Vol. 2. Current research and theory (pp. 453-481). New York: Appleton-Century-Crofts.

BuLL, J. A., III (1970). An interaction between appetitive Pavlovian CSs and instrumental avoidance responding. Learming \& Motivation, 1, 18-26.

DAvis, H. (1968). Conditioned suppression: A survey of the literature. Psychonomic Monograph Supplements, 2(14, Whole No. 30), 283-291.

Dickinson, A. (1977). Appetitive-aversive interactions: Superconditioning of fear by an appetitive CS. Quarterly Journal of Experimental Psychology, 29, 71-83.

DickInson, A., \& DearING, M. F. (1979). Appetitive-aversive interactions and inhibitory processes. In A. Dickinson \& R. A. Boakes
(Eds.), Mechanisms of learning and motivation: A memorial volume to Jerzy Konorski (pp. 203-231). Hillsdale, NJ: Erlbaum.

Dickinson, A., \& Pearce, J. M. (1977). Inhibitory interactions between appetitive and aversive stimuli. Psychological Bulletin, 84, 690-711.

Emurian, H. H., \& Weiss, S. J. (1972). Compounding discriminative stimuli controlling free-operant avoidance. Joumal of the Experimental Analysis of Behavior, 17, 249-256.

ESTES, W. K., SKINNER, B. F. (1941). Some quantitative properties of anxiety. Joumal of Experimental Psychology, 29, 390-400.

Fowler, H., FAGo, G. C., Domber, E. A., \& Hochhauser, M. (1973). Signaling and affective functions in Pavlovian conditioning. Animal Learning \& Behavior, 1, 81-89.

Grossen, N. E., Kostansek, D. J., Bolles, R. C. (1969). Effects of appetitive discriminative stimuli on avoidance behavior. Journal of Experimental Psychology, 81, 340-343.

HeRRnSteIn, R. J., \& Sidman, M. (1958). Avoidance conditioning as a factor in the effects of unavoidable shocks on food-reinforced behavior. Journal of Comparative \& Physiological Psychology, 51 , 380-385.

KnapP, R. K., Kause, R. H., \& Perkins, C. C., JR. (1959). Immediate vs. delayed shock in T-maze performance. Journal of Experimental Psychology, 58, 357-362.

KonorskI, J. (1967). Integrative activity of the brain. Chicago: University of Chicago Press.

LINDQUIST, E. F. (1953). Design and analysis of experiments in psychology and education. Boston: Houghton Mifflin.

MACKINTOSH, N. J. (1974). The psychology of animal learning. New York: Academic Press.

Meltzer, D., \& MASAKI, M. A. (1972). Stimulus parameters producing response summation. Psychonomic Science, 29, 155-157.

Millenson, J. R., \& DE Villiers, P. A. (1972). Motivational properties of conditioned anxiety. In R. M. Gilbert \& J. R. Millenson (Eds.), Reinforcement: Behavior analysis (pp. 97-128). New York: Academic Press.

Miller, L. (1969). Compounding pre-aversive stimuli. Journal of the Experimental Analysis of Behavior, 12, 293-299.

MILLER, L., ACKLEY, R. (1970). Summation of responding maintained by fixed-interval schedules. Journal of the Experimental Analysis of Behavior, 13, 199-203.

Overmier, J. B., Bull, J. A. III, \& PACK, K. (1971). On instrumental response interaction as explaining the influences of Pavlovian CSs upon avoidance behavior. Learning \& Motivation, 2, 103-112.

Overmier, J. B., \& LAWRY, J. A. (1979). Pavlovian conditioning and the mediation of behavior. In G. H. Bower (Ed.), The psychology of learning and motivation (Vol. 13, pp. 1-55). New York: Academic Press.

OVERMIER, J. B., \& SCHWARZKopf, K. H. (1974). Summation of foodand shock-based responding. Learning \& Motivation, 5, 42-52.

Rescorla, R. A., \& Solomon, R. L. (1967). Two-process learning theory: Relation between Pavlovian conditioning and instrumental learning. Psychological Review, 74, 151-182.

SCAvio, M. J., JR. (1974). Classical-classical transfer: Effects of prior aversive conditioning upon appetitive conditioning in rats. Journal of Comparative \& Physiological Psychology, 86, 107-115.

Sidman, M. (1960). Tactics of scientific research. New York: Basic Books.

Van Houten, R., O'Leary, K. D., \& Weiss, S. J. (1970). Summation of conditioned suppression. Journal of the Experimental Analysis of Behavior, 15, 117-121.

WEIss, S. J. (1964). Summation of response strengths instrumentally conditioned to stimuli in different sensory modalities. Journal of Experimental Psychology, 68, 151-155.

WEIss, S. J. (1969). Attentional processes along a composite stimulus continuum during free-operant summation. Journal of Experimental Psychology, 82, 22-27.

WEISs, S. J. (1970). An effective and economical sound attenuation chamber. Joumal of the Experimental Analysis of Behavior, 13, 37-39. 
WEISs, S. J. (1971). Discrimination training and stimulus compounding: Consideration of nonreinforcement and response differentiation consequences of $S^{\Delta}$. Journal of the Experimental Analysis of Behavior, $15,387-402$.

WEISS, S. J. (1976). Stimulus control of free-operant avoidance: The contribution of response and incentive relations between multipleschedule components. Learning \& Motivation, 7, 476-516.

Weiss, S. J. (1977). The isolation of stimulus-reinforcer associations established with multiple schedules. Animal Learning \& Behavior, 5, 421-429.

WEISS, S. J. (1978). Discriminated response and incentive processes in operant conditioning: A two-factor model of stimulus control. Journal of the Experimental Analysis of Behavior, 30, 361-381.

Weiss, S. J., \& EMURIAN, H. H. (1970). Stimulus control during the summation of conditioned suppression. Journal of Experimental Psychology, 85, 204-209.

WeISS, S. J., \& VAN OsT, S. L. (1974). Response discriminative and reinforcement factors in stimulus control of performance on multiple and chained schedules of reinforcement. Learning \& Motivation, 5 , 459-472.

\section{NOTE}

1. Although the original numerical data from the Overmier and Schwarzkopf (1974) study are no longer available, Bruce Overmier generously shared with us several remaining pretest baseline training and interaction test cumulative records generated by their dog Bathsheba. The training records clearly support our rate analysis of the Overmier and Schwarzkopf study explained above. The slope of the cumulative response pen in Phase 1 VR-3 appetitive training was $47.5^{\circ}$, whereas the Phase 2 (FOA baseline) slope was only $17^{\circ}$. Thus, in testing, an Sd that controlled almost three times the baseline rate was presented, meaning that a rate greater than baseline does not necessarily represent additive summation. For additive summation to be evidenced here, in testing the Sd would have to control a rate that produced a slope clearly greater than $47.5^{\circ}$. Although the slopes could only be roughly estimated from the 5-sec Sd presentations of the interaction test, they generally appeared to be within the range bracketed by the baseline and Sd slopes.

(Manuscript received July 7, 1988;

revision accepted for publication February 10, 1989.)

\section{Announcement}

\section{ScholarNet}

ScholarNet is an electronic network for the academic community. ScholarNet's divisions for the social sciences and humanities, PoliNet and HumaNet, offer members online discussion forums, file exchanges, E-mail, conference news, reviews, and newsletters devoted to a variety of academic topics.

M.A.C., The Macintosh in Academic Computing, is the most recent addition to the newsletter collection. Current articles include reports on courseware and statistics packages. Software (including HyperCard stacks) is available for downloading.

For information on obtaining an individual or departmental ScholarNet account, contact the Executive Editor, Michael L. Vasu, at North Carolina State University, Raleigh, NC 27695 (telephone: 919-737-3791). The editor of M.A.C. is Lee Sebastiani, 133 Handley St., Eynon, PA 18403 (telephone: 717-876-2417). 